\title{
A new design of support for burst-prone rock mass in underground ore mining
}

\author{
Krzysztof Skrzypkowski ${ }^{1, *}$ \\ ${ }^{1}$ AGH University of Science and Technology, Faculty of Mining and Geoengineering, 30 A. Mickiewicz Av., 30-059 Kraków, \\ Poland
}

\begin{abstract}
The article presents the basic methods of strengthening room and roadway excavations in underground ore mining. In particular, it was pointed out that the mining support is very often exposed to additional dynamic loads resulting from the mining of the deposit by means of explosives (slight) as well as from the load arising from rock mass tremors. In the article a new design of arch yielding support adapted to dynamic loads, which can be used in long-term access excavations was proposed. For this case, an exemplary spring deflection, which is located in the support foot cylinder, based on the principle of work and energy was calculated. In the case of exploitation room excavations, laboratory tensile tests of the long expansion rock bolt support, which were carried out in the rock bolting laboratory at the Department of Underground Mining AGH were presented. Loaddisplacement characteristics for long expansion rock bolt support with a particular indication of the elastic and plastic range were presented. In the summary, it was concluded that with the increase in the depth of exploitation, safe and efficient mining will be possible only due to the use of a support with appropriate yielding.
\end{abstract}

\section{Introduction}

Underground mining of ore deposits in Poland is carried out in Legnica - Głogów Copper Belt (LGCB) (copper ore) and in the Olkusz region (zinc and lead ore). The basic method of support access and exploitation excavations in both regions is the rock bolt support with the length in the range from $1.2 \mathrm{~m}$ to $2.6 \mathrm{~m}$. In mining excavations where an individual rock bolt support is applied, there is a risk of unintentional falling of rock blocks to the excavation. One of the conditions for the safe exploitation of ore deposits is the ability to maintain certain geometrical parameters of the room excavations over a certain period of time. In this case, the stability of the rooms is determined by the boundary span of the roof. In ore mining, there are cases that with spans smaller than the boundary, as a result of structural disturbances, local instability appears in the form of roof falls (Fig. 1a and $1 b)$ or stratification of the roof [1].

\section{Dynamic loading in underground ore mining}

From among many factors affecting the stability of mining excavations, rockbursts and tremors play a special role. In deep mines exploiting ore deposits, rockbursts and tremors occur practically always and have different sources of generation. The most important of them is the commonly used mining technique, which

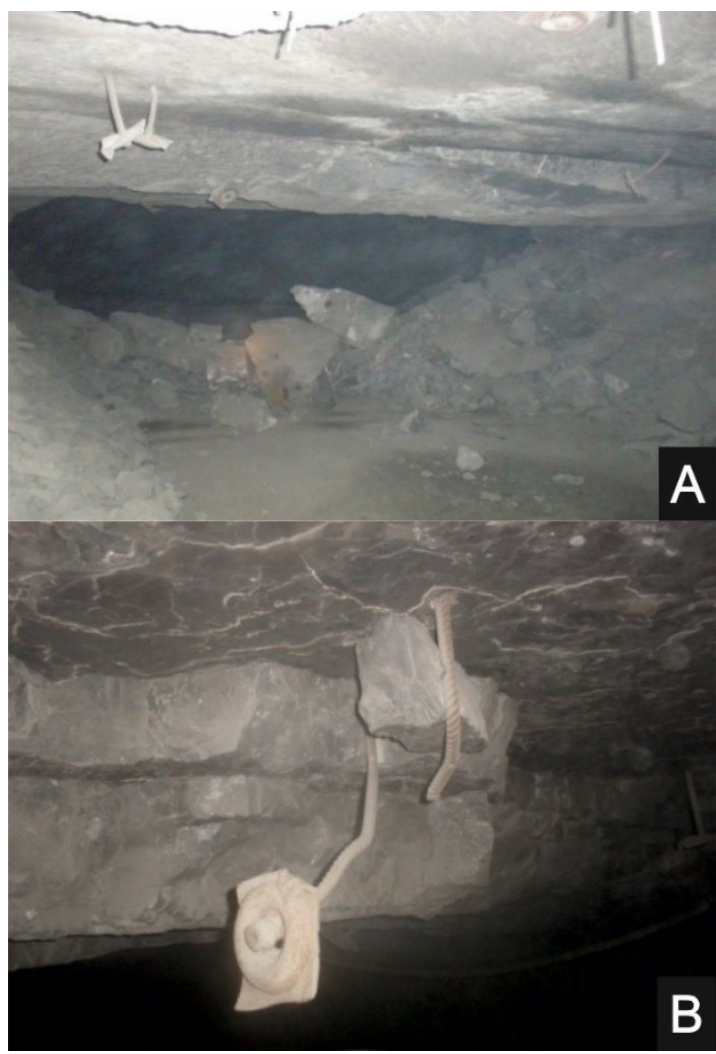

Fig. 1. Roof falls in one of the underground ore mines in the Legnica-Głogów Copper Belt; A) partial filled room by means of roof rocks, B) roof falls of stratificated roof layers.

\footnotetext{
* Corresponding author: skrzypko@agh.edu.pl
} 
Table 1. Amount of rock mass tremors and induced seismic energy in one mine of KGHM Polska Miedź S.A.

\begin{tabular}{|c|c|c|c|c|c|c|c|c|c|c|c|}
\hline year & $\mathbf{1 0}^{\mathbf{1}}[\mathbf{J}]$ & $\mathbf{1 0}^{\mathbf{2}}[\mathbf{J}]$ & $\mathbf{1 0}^{\mathbf{3}}[\mathbf{J}]$ & $\mathbf{1 0}^{\mathbf{4}}[\mathbf{J}]$ & $\mathbf{1 0}^{\mathbf{5}}[\mathbf{J}]$ & $\mathbf{1 0}^{\mathbf{6}}[\mathbf{J}]$ & $\mathbf{1 0}^{\mathbf{7}}[\mathbf{J}]$ & $\mathbf{1 0}^{\mathbf{8}}[\mathbf{J}]$ & $\mathbf{1 0}^{\mathbf{9}}[\mathbf{J}]$ & sum $[\mathbf{a m o u n t}]$ & $\mathbf{\Sigma} \mathbf{E}[\mathbf{J}]$ \\
\hline $\mathbf{2 0 1 0}$ & 12189 & 1454 & 1248 & 510 & 193 & 55 & 27 & 2 & 0 & 15678 & $1.16 \cdot 10^{9}$ \\
\hline $\mathbf{2 0 1 1}$ & 12294 & 1451 & 1454 & 629 & 212 & 80 & 23 & 0 & 0 & 16143 & $8.20 \cdot 10^{8}$ \\
\hline $\mathbf{2 0 1 2}$ & 14021 & 1363 & 1304 & 678 & 187 & 47 & 20 & 0 & 0 & 17620 & $6.96 \cdot 10^{8}$ \\
\hline $\mathbf{2 0 1 3}$ & 15251 & 1929 & 1639 & 730 & 200 & 57 & 10 & 1 & 0 & 19817 & $6.53 \cdot 10^{8}$ \\
\hline $\mathbf{2 0 1 4}$ & 14677 & 2144 & 1828 & 739 & 235 & 56 & 6 & 0 & 0 & 19685 & $4.47 \cdot 10^{8}$ \\
\hline $\mathbf{2 0 1 5}$ & 13942 & 2298 & 1674 & 642 & 232 & 54 & 4 & 1 & 0 & 18847 & $5.70 \cdot 10^{8}$ \\
\hline
\end{tabular}

disintegrates a certain area of the rock mass not only in the area of the planned mining, but also creates waves that significantly exceed this area and also to some extent destroy the center structure. For example, in one of the underground copper ore mines of the LGCB region, about $30 \mathrm{Mg}$ of explosives are consumed daily. The use of rock mass stress-relief blasting has positive effects in relation to rockburst prevention, but it can also negatively affect the elements that ensure the stability of the excavation the rock bolt supports. Regardless of blasting induced provoked by mining works, there are also rock mass tremors resulting indirectly from the exploitation of the deposit. The latter are difficult to predict and because of the huge released energy, reaching the value of $10^{9} \mathrm{~J}$, they are very dangerous in consequences. The amount of rock mass tremors and released energy in the 6-year period for one of the underground copper ore mines of the LGCB region is shown in Table 1.

From the experience of the mines, it appears that the loss of load capacity of the bolt is not always proportional to the released energy. It happens many times that the bolt support remains intact even after strong tremors, in the relationship of energy class varies from $10^{8}$ to $10^{9} \mathrm{~J}$, and after low-energy tremors there were cases of destruction of the bolt support [2]. A parameter that can be helpful and measurable with the impact of seismic energy of rock mass tremors on the roof falls is the peak particle velocity of the rock mass caused by the seismic event. Korzeniowski [2] carrying out research in the underground copper ore mines of the LGCB region, stated that the highest convergence of results taking into account the frequency of occurrence of roof falls on the one hand and the frequency and location of tremors with a given energy takes place for the formula [3]:

$$
p p v=2650 \cdot\left(\frac{R}{10^{\frac{M}{3}}}\right)^{-1.36}
$$

After taking into account the dependence between the magnitude of the tremor energy E $[\mathrm{J}]$ and the local magnitude of Richter $M$ according to the following formula:

$$
\log E=1.15+1.96 M
$$

The value of the magnitude $M$ depends on the mechanism of the source of the tremor [4]:

- ejection of larger, previously formed rock blocks, e.g. due to buckling of layers $(M=0 \div 1.5)$,
- sudden exceeding of the load bearing capacity of the pillar $(M=1.0 \div 2.5)$,

- rapid shearing and spreading of fissures $(M=2.0 \div 3.5)$, - slip along the fault surface $(M=2.5 \div 5.0)$.

Unmistakable determination of the critical peak particle velocity of the rock mass for the stability of the excavation is difficult and depending on the local conditions of the rock mass. Korzeniowski [2] used the criteria for the scale of the excavation risk and the loss of stability depending on the ppv value according to the criteria given in Table 2 .

Table 1. Setting Word's margins.

\begin{tabular}{|c|c|}
\hline $\begin{array}{c}\text { ppv value } \\
{[\mathbf{m m} / \mathbf{s}]}\end{array}$ & Roof falls \\
\hline$<\mathbf{5 0}$ & $\begin{array}{c}\text { there is no damage for rock mass } \\
\text { (lack of roof falls) }\end{array}$ \\
\hline $\mathbf{5 0} \div \mathbf{3 0 0}$ & $\begin{array}{c}\text { formed roof falls of loose rocks } \\
\text { (average roof falls) }\end{array}$ \\
\hline $\mathbf{3 0 0} \div \mathbf{6 0 0}$ & $\begin{array}{c}\text { formed roof falls with increased range } \\
\text { (high roof falls) }\end{array}$ \\
\hline$>\mathbf{6 0 0}$ & $\begin{array}{c}\text { very extensive roof falls } \\
\text { and serious damages are observed }\end{array}$ \\
\hline
\end{tabular}

In the field of predicting the impact of tremors caused by the use of explosives on the stability of the bolted roof in literature, the maximum peak particle velocity of rock mass is considered a criterion for damage to the excavations in the rock bolt support. The empirical and theoretical formulas are used assuming different limiting values of ppv, with the ppv value $>200 \mathrm{~mm} / \mathrm{s}$ being most often given. The size of ppv can be determined from the relationship [5]:

$$
p p v=650 \cdot\left[\frac{\sqrt{f \cdot Q}}{R}\right]^{1.42}
$$

where:

$$
f=\frac{\operatorname{arctg}\left(\frac{H}{2 R}\right)}{\frac{H}{2 R}}
$$

$Q$ - mass of explosive charge, $\mathrm{kg}$,

$R$ - distance from the blasting cartridge, $\mathrm{m}$,

$H$ - length of blasting cartridge, $\mathrm{m}$.

Based on Korzeniowski's research and observations [2] in underground mining excavations, it should be noted 
that for Polish copper ore mines, the $200 \mathrm{~mm} / \mathrm{s}$ hazard thresholds and the $600 \mathrm{~mm} / \mathrm{s}$ damage are underestimated.

In all LGCB mines there are rock mass tremors, which are recorded in real time in a three-dimensional system, which facilitates taking into account their influence when analyzing other results of measurements carried out in mines. Based on Table 1 for 2015 , it can be concluded that tremors with low energies, below $10^{3}[\mathrm{~J}]$, are most common. Tremors with energy $10^{4}[\mathrm{~J}]$ represent more than $15 \%$ of all tremors (without residuals). The share of major tremors with energy above $105[\mathrm{~J}]$ does not exceed, in general, $1.2 \%$ of all tremors. Despite the fact that in the majority of cases there are no visible changes in the roof and rock bolt support after the occurring tremors, there are some characteristic phenomena in the roof, especially strongly stratified and in the roof with the rock bolt support, namely:

- cases of breaks of rock bolts when roof rock fall, only a

few dozen centimeters in thickness,

- formation of fissures and cracks between the bolted layers, and consequently the loss of individual rock blocks,

- roof rock fall,

- covering of rocks around the bearing plate,

- loss of small rock fragments between the rock bolts,

- loss in pre-tensioning of expansion rock bolts within several dozen percent.

The above mentioned effects of roof destruction are usually visible only after a certain period of time.

\section{Additional reinforcement underground ore mining}

\subsection{Additional mining support for underground exploitation of zinc and lead ore deposits}

For the underground exploitation of lead zinc ore deposits, the bolt support is the basic method of securing roadway and room excavations. The $1.6 \mathrm{~m}$ long rock bolt support with net bolting of $1 \times 1 \mathrm{~m}$, is commonly used [6, 7]. The additional support is used in excavations in which roof disturbances have arisen in the form of a gap, a threshold and a gap with a height of up to $0.7 \mathrm{~m}$, and 0.8 $\mathrm{m}$ and above these values (Fig. 2a). Most often, an additional row of rock bolts are used along with the roof mine mesh (MM). In addition, in excavations that require additional support, e.g. at crossings, a wooden cribs are additionally used. The cribs are built of wooden beams with a diameter of 0.1 to $0.3 \mathrm{~m}$. The beams of the crib are joined with steel braces. The wooden cribs are empty (Fig. $2 b)$. Particularly for the fifth roof class in the "Olkusz Pomorzany" mine, the arch yielding support, type ŁP9 is used, with a height of $3.5 \mathrm{~m}$ and a width of $5 \mathrm{~m}$ at a spacing of $0.5 \mathrm{~m}$ or $1 \mathrm{~m}$ (Fig. 2c). The roof lagging is full made of reinforced concrete lining elements, metal lining or welded facing mesh. Sidewalls arches in excavations, whose floor are rocks with compressive strength $>30$ $\mathrm{MPa}$, are located directly on the floor in sockets with a depth of $0.05 \div 0.10 \mathrm{~m}$. In rocks with compressive strength in the range of $4 \div 30 \mathrm{MPa}$, sidewalls arches are placed on steel supporting feet or foundation concrete. For excavations whose floor consists of rocks with a compressive strength $<4 \mathrm{MPa}$ or sand, sidewall arches should be placed on foundation concrete with an surface area of min. $600 \mathrm{~cm}^{2}$. In particular, at crossings of excavations, an additional $2.5 \mathrm{~m}$ long rock bolt is installed with special wooden discs that act as a locator of stratification of roofs (Fig. 2d).

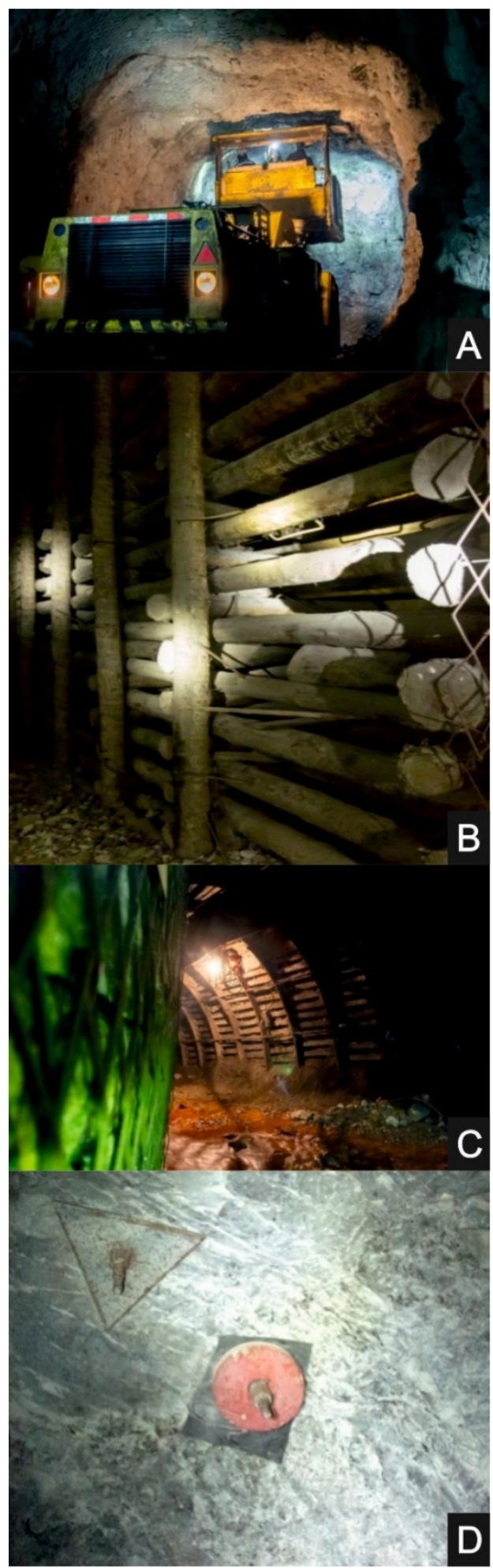

Fig. 2. Additional support of excavations: A) installing of manual rock bolt with steel mesh, B) mining cribs, C) sidewall arch with openwork lagging made by reinforced concrete facing, D) signaling device for roofs stratifications. 


\subsection{Additional mining support for underground exploitation of copper ore deposits}

In the underground mines of the LGCB, the basic support of the preparatory and exploitation excavations are rock bolts with expansion shells and steel bolts installed with resin cartridges. The length of the bolt rods varies from 1.2 to $2.6 \mathrm{~m}$. Bolting net is $1 \times 1 \mathrm{~m}, 1.5 \times 1.5$ $\mathrm{m}$ and $2.0 \times 2.0 \mathrm{~m}$. Annually about $2.5 \div 3$ millions units of bolts are used in underground Polish copper ore mines [8]. The choice of the excavation support is made by the manager of the Mining Department on the basis of understanding the geological and mining conditions. In practice, this insight is implemented by determining the roof class, in accordance with the instruction used by LGCB mines [9], developed by an expert. In room-andpillar mining systems of copper ore deposits, as the exploitation front moves, crushing of the body pillar, creep of the sidewalls and change of the extent of excavations occur [10]. To maintain the right inclination of the sidewalls in the direction of the body of ore, a floor ripping is used. During this treatment there are spontaneous cases of local expansion of excavations above the planned dimensions. In places of widening excavations or deteriorated floor conditions, an additional reinforcing support is used. One of the methods of additional reinforcement is bolting over $2.6 \mathrm{~m}$. Very often cable-cement bolts, with a length of $5 \mathrm{~m}$ and $7 \mathrm{~m}$ (Figs. 3a, 3b) for example, type KL-15.5; KL-15.5K are used. The cable-cement technology is as follows: drill bolt holes with a diameter of at least $25 \mathrm{~mm}$ for a smooth cable or $38 \mathrm{~mm}$ diameter for a cage cable and the appropriate length. Prepare the cable for installation (attach a vent pipe with a diameter of $\varnothing 6 \mathrm{~mm}$ or a diameter of $8 \mathrm{~mm}$ to the rope). Then, put the cable into the hole so that a line from $150 \mathrm{~cm}$ to $200 \mathrm{~cm}$ length protrudes from the hole. Next, insert and expand the injection head in the hole. Mix the cement and water mortar in the mixer. The mortar should be pressed until it emerges from the venting tube of the cement milk or the air outflow. After 24 hours, install the support bearing plate on the cemented cables the M30 bushing and the M30 nut (if there is a bolt included) and the clamp. In the case of using the M30 tension sleeve and the M30 nut, the bolt should be given a preload, with a value not less than $30 \mathrm{kN}$. The pretensioning is given by a torque wrench by tightening the M30 nut with a torque of not less than $60 \mathrm{Nm}$. The minimum load capacity of cable-cement bolt is $150 \mathrm{kN}$ [11]. For long bolting of mining excavations, a selfpropelled car for cable-cement bolt - WCKL is used. Drilling of technological holes, making the bolting support and other auxiliary works is carried out from the working platform. The number of additional installed long bolts is around $10 \div 11$ thousand units per year [8].

An alternative for cable-cement bolts over $2.6 \mathrm{~m}$ are expansion rock bolts, type OB25 or OB28 [6, 7]. Expansion rock bolt support type $\mathrm{OB}$ consists of an expansion shell, steel rod, bearing plater, nut and connecting sleeves. A characteristic feature of this bolt is the possibility of joining steel rods with a length of $1.7 \mathrm{~m}$ by means of connecting sleeves (Fig. 4a). An expansion sleeve comprising at least two jaws attached to the spreader (rod) by means of at least one puller (Fig. 4b). This type of support can be installed in the same process as the short support (up to $2.6 \mathrm{~m}$ ).

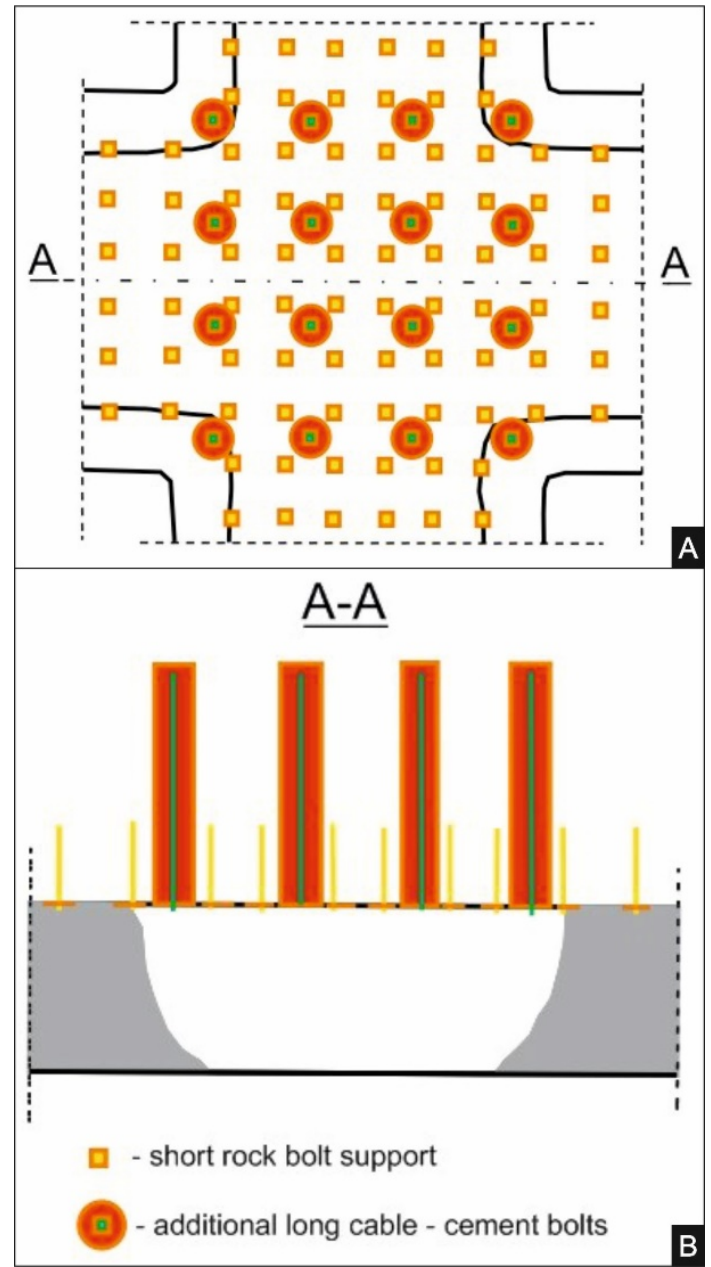

Fig. 3. Long cable bolts in cement grout; a) top view, b) crosssection through the widen room.

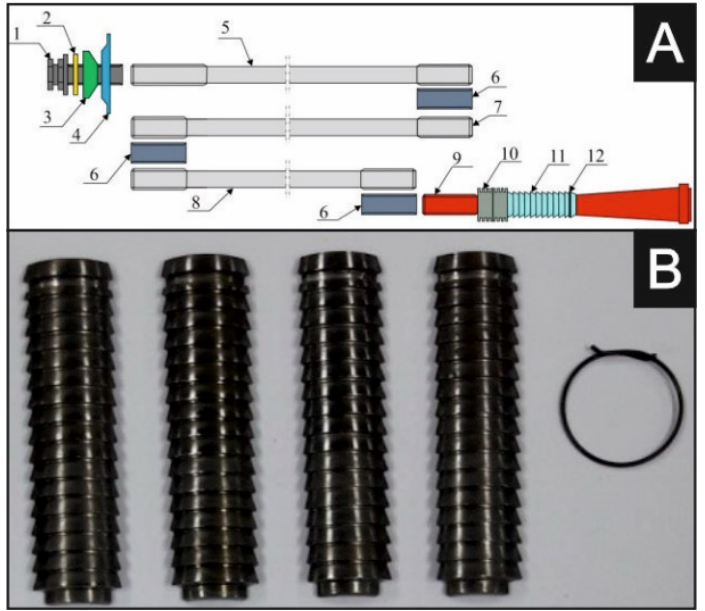

Fig. 4. Long expansive connected rock bolt support (5.2 m); A) elements of bolt support; 1 - sleeve with hexagonal end, 2 plastic washer, 3 - dome washer, 4 - bearing plate, 5 - bolt rod, 6 - connecting sleeve, 7 - intermediate bolt rod, 8 - connecting bolt rod with expansion head, 9 - expansion head, 10 - plastic puller, 11 - leaves, 12 - steel puller, B) shellsof. 
The rock bolt support can be additionally reinforced by means of roof beams, which are installed to the roof with resin or expansion bolts. They are installed in the places of the expected roof falls or intervening in places where the roof fissures appear. Roof beams are installed in the places where the continuity of roof layers are interrupted as a result of the stratification of rock mass. In addition, the roofs and sidewalls of excavations are supported with metal mesh or fiberglass, composite or polyester geogrids. In spite of the significant technical progress that has been made in recent years in the field of mining technology, wood has been used for the mining excavations to date. In the underground mines of the LGCB, the wooden support is used in the form of individual props, rows of props as a partition and reinforcement of areas threatened by the roof falls or a group of props as reinforcement of workings crossings [12]. Rows of wooden props constitute a local barrier against the spreading of rock falls. The wooden support is also used to build wooden cribs which are placed in the middle of the excavation span or near the sidewall. Cribs built in the middle of the excavation form a reinforcement element for the rock bolt support and at the same time serve as an element separating access to the section endangered by the roof falls. Stacks at the sidewalls, mainly in the corners of the extended crossings, constitute a support that reduces the spread span of the excavation. The filling of the cribs with waste rock increases its carrying capacity several times, which contributes to the utilization of waste rocks in situ conditions. Individual wooden props are set in places indicating the separation of floor layers. Currently, hydraulic props are used more often as local reinforcement of the roof, instead of wooden props. The modular structure of the HYDROTECH14/53-P-M support consists of several basic elements: a roof base, a floor base, a hydraulic prop (optionally extended with a mechanical extension), fasteners (bolts and securing devices) connecting the main components and the so-called the hydraulic system or valve block with lines, hydraulic connectors and manometric indicators. The prop support has the possibility of inclination of $+/-$ $15^{\circ}$ in each direction from the axis of the socket, both the floor base and the roof base, in order to better adapt to the geometry of the excavation. The HYDROTECH-14/53-PM support can be used in four sizes with the possibility of supplementing the height with additional mechanical extensions. The range of work heights ranges from 1.4 to $2.15 \mathrm{~m}+\max .1 .5 \mathrm{~m}$, from 1.4 to $2.7 \mathrm{~m}+\max .1 .5 \mathrm{~m}$, from 2.2 to $3.7 \mathrm{~m}+\max .1 .5 \mathrm{~m}$ and from 1.9 to $4.2 \mathrm{~m}+$ max. $1.5 \mathrm{~m}$. The support can work in a no seismically active rock mass with a minimum reserve of $0.2 \mathrm{~m}$, while in a rock burst prone rock mass with a minimum reserve of $0.3 \mathrm{~m}$ in the lower limit of the work range. The support is fed with an oil-water emulsion from the SWOI engine unit with a pressure of $31.5 \mathrm{MPa}$. Permanent working capacity support is maintained by a valve block with a setting of $48 \mathrm{MPa}$ for telescopic props and $35 \mathrm{MPa}$ for single stage props. The support is designed to transfer working load up to $950 \mathrm{kN}$ and can work depending on the type of prop with working load capacity of $700 \mathrm{kN}$ or $950 \mathrm{kN}$ [13].

\section{Load - displacement characteristics for long expansion rock bolt support}

The laboratory tensile tests of the expansion rock bolt support were carried out on the laboratory stand of the Underground Mining Department simulating mine conditions, in particular for the mines of KGHM Polska Miedź S.A. The aim of the research was to obtain loaddisplacement characteristics. The research was carried out according to a uniform methodology. The increase in the load of the tested bolt and the time of its suspension was carried out by means of a pressure reducer, until the bolt was completely broken. Tensile testing of the bolt support consisted of a periodical pressure increase of $1 \mathrm{MPa}$, which was carried out using the reduction valve located on the control panel. Each pressure increase was preceded by a holding time of 30 seconds. The bolt load was made by using a hydraulic system, which consists of a support frame on which a block of 8 hydraulic cylinders was installed. Because long bolt were used in the tests, additionally two-part sleeves and a cylinder filled with a core taken from the mine were placed on the supporting frame behind the cylinder block. The force measurement at the laboratory test facility was carried out using four strain gauges. The measurement of displacements of the support elements and the elongation of the rock bolt was carried out using an incremental wire encoder. The force and displacement sensors were connected to the QuantumX MX840 universal measuring amplifier. During the bolt tensile process, the results of force and displacement measurements were recorded on an ongoing basis using the specialized "CATMAN - EASY" program [14]. The power supply of the system was provided by a hydraulic power supply unit built on the basis of a multipiston variable displacement pump with constant power and constant pressure regulators. The maximum supply pressure was $31 \mathrm{MPa}$. In order to reflect the mining conditions, a steel cylinder with an outside diameter of $0.102 \mathrm{~m}$ and a length of $0.6 \mathrm{~m}$ was used in the laboratory test facility, which was filled with a rock core (dolomite) from the roof stratum (Fig. 5). The dolomite had a compressive strength of at least $100 \mathrm{MPa}$. The core had a diameter of $0.09 \mathrm{~m}$ and was fixed to the pipe with a polyester resin. The core has a hole with a diameter of $0.0254 \mathrm{~m}$ for an expansion head with a diameter of 0.025 $\mathrm{m}$. The axially placed holes have the same diameter as the holes made in the roofs of the mining drifts. The bolt rods were connected and inserted manually into the steel cylinder through the measuring target, the hole in the hydraulic load arrangement of the bolts and the dual cylinders, which constituted the distance. A steel cylinder with a rock core was located at the end of the dual cylinder.

One point of expansion was installed expansion shell in the rock core (Fig. 6), while the second point of expansion was the sleeve nut, preceded by a gasket, ball washer and profiled bearing plate resting on the movable target of the hydraulic bolt load device. Then, the bolt in the hole was installed using a force of $300 \mathrm{Nm}$, which corresponded to the pre-tensioning force at the level above $60 \mathrm{kN}$ (Fig. 7). In the research, an expansion rock 
bolt support with a total length of $5.2 \mathrm{~m}$ (Figs. 4, 6) was used, which constitutes an additional support for exploitation excavations and is increasingly used to reinforce roofs and rebuildings in underground mines belonging to KGHM. The rock bolts were made of steel grade OB640 (factory standard). Long expansion bolt type OB25 consists of an expansion shell with a diameter of $0.0254 \mathrm{~m}$, three smooth steel rods with a diameter of $0.0183 \mathrm{~m}$ (two bolt rods with a length of $1.7 \mathrm{~m}$ and one with a length of $1.5 \mathrm{~m}$ ), three connecting sleeves with a diameter of $0.0254 \mathrm{~m}$ and a height of $0.065 \mathrm{~m}$, a shaped bearing plate with side length $0.145 \div 0.155 \mathrm{~m}$ and thickness $0.006 \mathrm{~m}$, ball washer diameter $0.055 \mathrm{~m}$, sleeve nut $0.065 \mathrm{~m}$ high ended with hexagon head (M20) and gaskets. The expanding shell with a length of $0.240 \mathrm{~m}$ consists of a spanner (the rod of which one side is provided with a known threaded tip and the other one is a conical part with a length of $0.107 \mathrm{~m}$, which terminates with a $0.016 \mathrm{~m}$ long stub), two plastic brake sleeves and an expansion sleeve that contains four jaws with a length of $0.075 \mathrm{~m}$ attached to the spreader (rod) using a round and flat puller. Examples of characteristic parameters obtained during the tests are shown in Figure 7.

Analyzing the load - displacements characteristics shown in figure 7, it can be concluded that the maximum breaking force ranged from $212 \mathrm{kN}$ to $215 \mathrm{kN}$ with a displacement in the range from $0.355 \mathrm{~m}$ to $0.380 \mathrm{~m}$, for which the material continuity was interrupted on the connecting rod. In all cases, a pre-tension of over $50 \mathrm{kN}$ caused the bolt to move up to $0.004 \mathrm{~m}$. During the tests, the elastic range was recorded up to a load of $160 \mathrm{kN}$ which corresponded to a displacement in the range from $0.038 \mathrm{~m}$ to $0.042 \mathrm{~m}$.

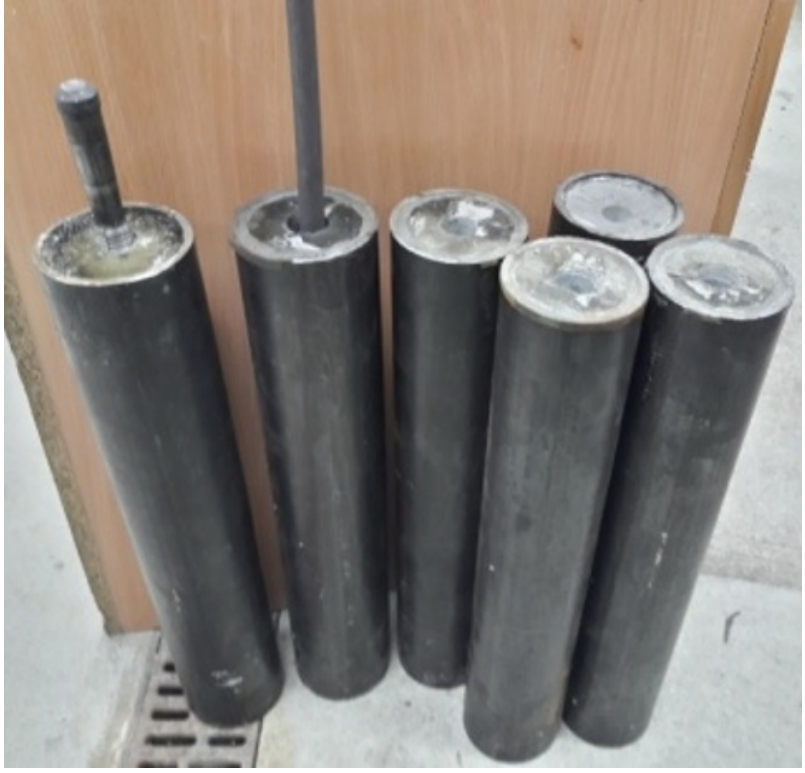

Fig. 5. Cylinders with core rocks.

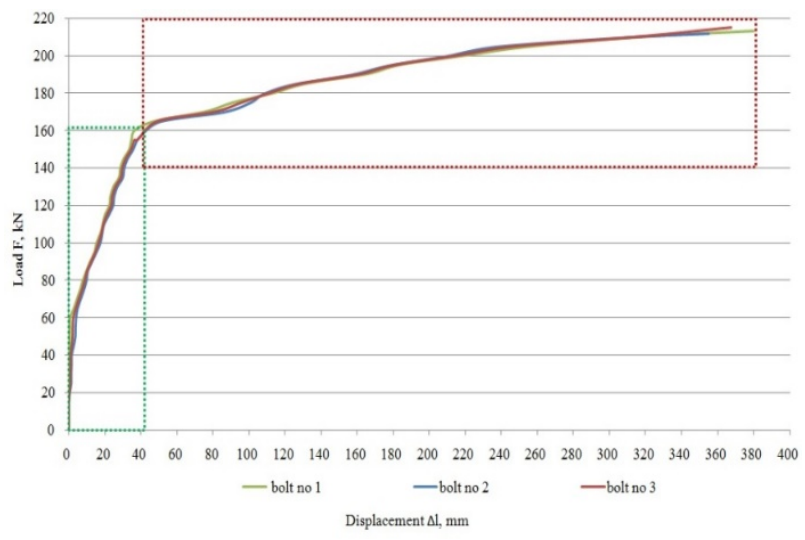

Fig. 7. Load - displacement characteristics of expansion rock bolt OB25 with length of $5.2 \mathrm{~m}$.

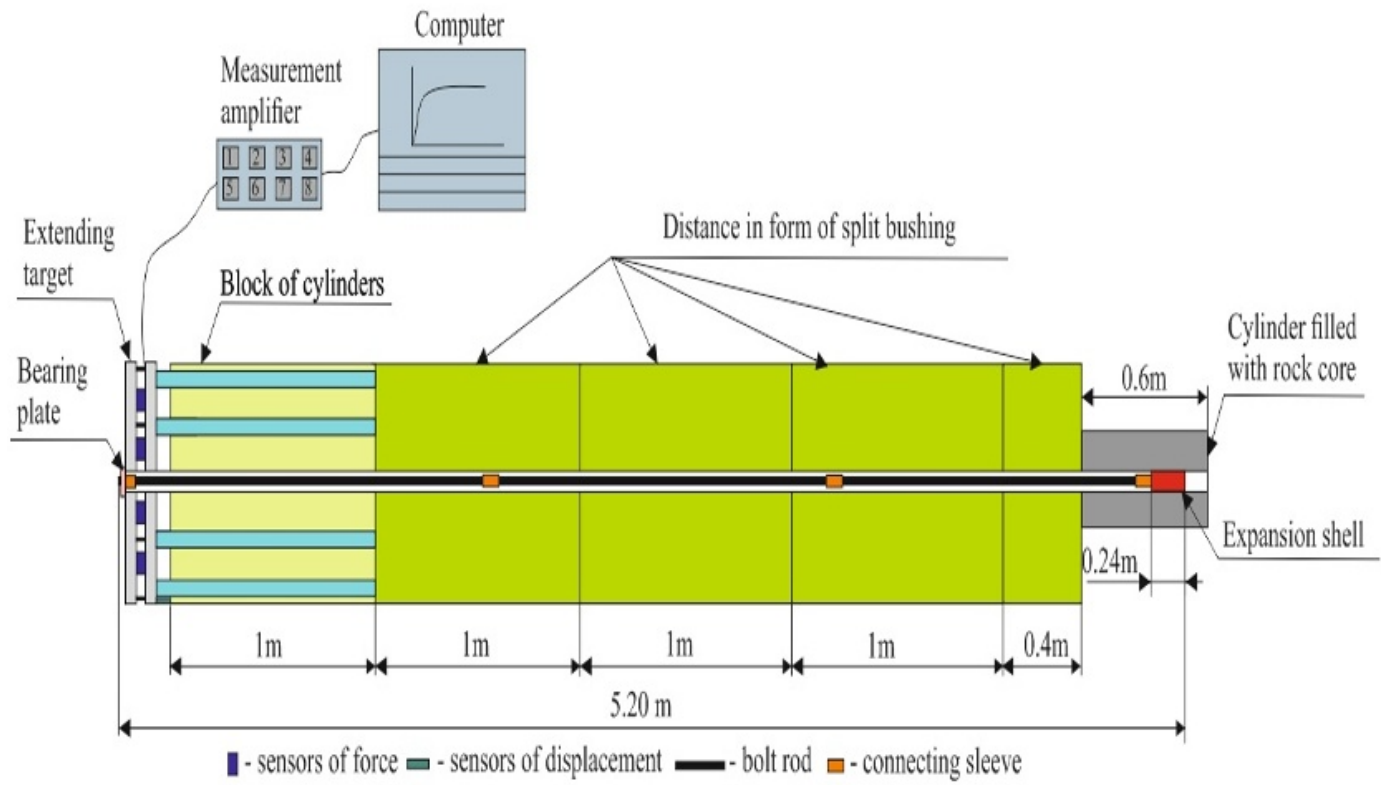

Fig. 6. Laboratory test facility. 


\section{New design of arch yielding support}

The choice of support for excavations in the conditions of increasing operating pressures and the threat of rock bursts is one of the most important tasks faced by the technology of underground mining. The successive depletion of deposits of both ore and hard coal in Poland means that their exploitation takes place at ever greater depths. Currently, in Poland, we mean $1000 \mathrm{~m}$ and more when talking about deep mines. For example, in the hard coal mine "Budryk", the level at the depth of $1290 \mathrm{~m}$ is made available, which means that it is the deepest hard coal mine in Poland. The copper ore deposit in LGCB in currently active exploitation fields lies at a depth varying from 500 to $1250 \mathrm{~m}$. In undeveloped fields, the copper ore deposit is recognized to a depth of $1500 \mathrm{~m}$. With depth, a marked reduction in the thickness of the deposit is observed [15]. The depth of mining works increases from $5 \mathrm{~m}$ to $8 \mathrm{~m}$ each year.

\subsection{Description of new design of arch yielding support}

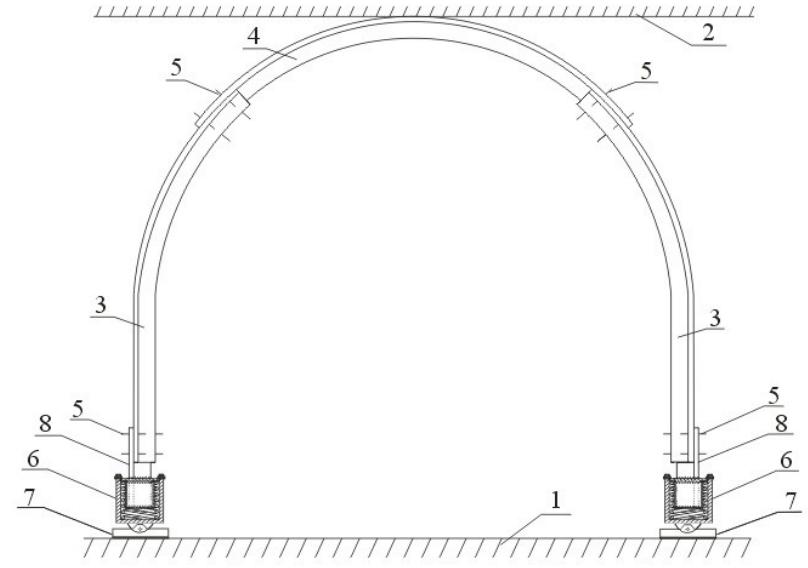

Fig. 8. Arch yielding support of preparatory excavations; $1-$ floor, 2 - roof, 3 - arch sidewall, 4 - roof arch, 5 - arch connection (yoke and stirrup), 6 - yielding cylinder, 7 support foot, 8 - additional straight short section of support [16].

The yielding support of a roadway excavations (Fig. 8) is characterized by the fact that on the floor of the excavation (1) there is a support foot (7) on which there are two yielding cylinders (6) enabling the construction of two sidewalls arches at the same time with a set distance (Fig. 9). The support foot has a round rods (9) welded on the side of the floor to increase stability. The support foot is a reusable element. The yielding cylinders in the bottom part have rotary seats (10), through which the support can be used in inclined excavations. Each yielding cylinder is connected to the arch by means of locks (5). In the upper part of the yielding cylinder, there is an additional straight section of the arch yielding support (8), used to connect the side arch (legs). A yielding cylinder (6) characterized in that it consists of an articulated cylinder (12) which is mounted on the support foot (7) by means of a pin (13). In the middle of the cylinder there is an additive spring (11) on which an inner cylinder with a collar (14) operates, to which an additional straight section of the side $\operatorname{arch}(8)$ is welded, which is connected by a lock (5) to the side $\operatorname{arch}(3)$.

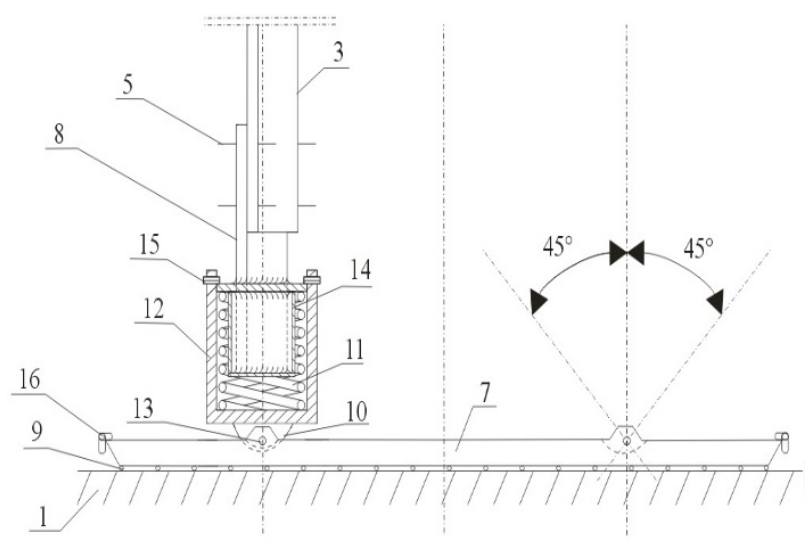

Fig. 9. Arrangement of yielding cylinder on the support foot; 1 - floor, 2 - roof, 3 - sidewall arch, 4 - roof arch, 5 -connection between sections (yoke and stirrup), 6 - yielding cylinder, 7 support foot, 8 - additional straight short section of support, 9 steel rods, 10 - rotary socket, 11 - yielding spring, 12 articulated joint cylinder, 13 - pin, 14 - inner cylinder with a collar, 15 - protection of the internal cylinder, 16 - handle for transporting the support foot [16].

\subsection{Deflexion of spring}

Consider the case in which the roof rocks $A$ with weight $P$ fall from the height $\mathrm{h}$ without the initial speed to the plate $B$ with the weight $p$. The plate is installed on a spring with stiffness $c$. We are interested in s spring deflection, assuming that the coefficient of restitution $k$ is equal 0 . The velocity u of the roof rocks $A$ at the time of touching plate $B$ can be expressed by the following formula:

$$
u=\sqrt{2 \cdot g \cdot h}
$$

Inelastic collision, so:

$$
\mathrm{u}_{2}=\mathrm{u}_{1}=\mathrm{u}
$$

Equation of momentum conservation:

$$
\begin{gathered}
\frac{P}{g} \cdot \sqrt{2 g h}=\frac{P+p}{g} \cdot u \\
u=\frac{P}{P+p} \cdot \sqrt{2 g h}
\end{gathered}
$$

The deflection $s$ of the spring is calculated based on the principle of work and energy. It should be taken into account that at rest the spring has a deflection $s_{0}$ under the body weight $p$ (Fig. 10):

$$
\begin{gathered}
s_{0}=\frac{p}{c} \\
\frac{P+p}{2 \cdot g} \cdot u^{2}+(P+p) \cdot s=\frac{c}{2} \cdot\left(s+\frac{p}{c}\right)^{2}-\frac{c}{2} \cdot s_{0}^{2}
\end{gathered}
$$




$$
\begin{gathered}
\frac{2 \cdot h \cdot P^{2}}{(P+p)}+2 \cdot(P+p) \cdot s=c \cdot s^{2}+2 \cdot s \cdot p \\
s^{2}-\frac{2 \cdot P \cdot s}{c}-\frac{2 \cdot h \cdot P^{2}}{(P+p)}=0 \\
s=\frac{P}{c}+\sqrt{\frac{P^{2}}{c^{2}}+\frac{2 \cdot h \cdot P^{2}}{c \cdot(P+p)}}
\end{gathered}
$$

times of expansion bolts with cable-cement bolts, it should be stated that for expansion bolts, the entire structure of one bolt does not last longer than 10 minutes, in the case of full cable-cement bolt only after one day. This is mainly related to the bonding time of the cement mortar.

On the other hand, in underground zinc and lead mine in Poland, the basic support is resin steel bolts. The essential threat may appear in the case of weathered rock, which is characteristic feature of the Olkusz region (roof rocks with compressive strength in the range from $20 \mathrm{kN}$ to $200 \mathrm{kN})$.

Laboratory tension tests of the $5.2 \mathrm{~m}$ long expansion bolts were made on a modern bolt laboratory of the AGH Underground Mining Department, enabling testing of bolts in 1:1 scale with rod lengths up to $6 \mathrm{~m}$. Considering the minimum load capacity of the rock bolt support, which for copper ore mining is $100 \mathrm{kN}$ it should be noted that the long expansion rock bolt support with a length $5.25 \mathrm{~m}$, type OB25 works with a factor of safety above 2 . The depth of exploitation has a particular importance in the case of mining ore deposits in the Legnica-Głogów Copper Belt. Currently, the operation is carried out at a depth of up to $1250 \mathrm{~m}$. It is planned that the exploitation of the new Głogów Głęboki - Przemysłowy deposit will be carried out at a depth of $1300 \div 1400 \mathrm{~m}$. The bolt support is the basic technological operation strengthening the roof of the excavation. However, there are places that are characterized by local instability in the form of roof falls. In such conditions, an additional support is often used. The concept of a new yielding support with a yielding cylinder can contribute to limiting the impact of rock mass tremors in such a way that the excavation or its section does not lose functionality and safety of its use. Yielding eliminates the sinking of the sidewall arches into the floor of the excavation, thanks to which the original cross section of the excavation is maintained. Under the influence of dynamic load, the yielding spring is deflected, which contributes to absorbing vibrations of the rock mass.

The study was carried out within the framework of statutory work no. 15.11.100.005.

\section{Conclusions}

The basic task to be faced with each mining support is to protect excavations against the roof falls. The variety of lithological types of roof rocks within the access and exploitation excavations, as well as the tendency of the rock mass to tremors, causes that some roofs have tendency to roof fall or collapse in a very short period of time from their unveiling. In underground mining excavations of Legnica - Głogów Copper Belt, long bolting in form of cable-cement bolts with a length of $5 \mathrm{~m}$ and $7 \mathrm{~m}$ at the level of about 11 thousand units annually in one Mining Department are used. Nowadays, a long connected expansion rock bolt support is used more and more often to reinforce roofs and for rebuildings. A characteristic feature of this bolt is the possibility of joining steel rods of any length, usually $1.7 \mathrm{~m}$ with the use of connecting sleeves. When comparing the installation

\section{References}

1. K. Skrzypkowski, W. Korzeniowski, K. Zagórski, P. Dudek, Studia Geotechnica et Mechanica, 39, 3 (2017)

2. W. Korzeniowski, AGH, Dissertations, Monographs, 156 (2006)

3. R.E. Goodman, K. Te-Chih, Advances in computation of jointed rock. Computer Methods and Advances in Geomechanics (A.A. Balkema, Rotterdam, 1995)

4. W.D. Ortlepp, Proc. Of Int. Conf. Rockburst and seismicity in mines, (A.A. Balkema, Rotterdam, 1993)

5. B. Mohanty, Rock fragmentation by blasting (A.A. Balkema, Rotterdam, 1996) 
6. K. Skrzypkowski, E3S Web of Conferences, 29, 00004 (2018)

7. K. Skrzypkowski, E3S Web of Conferences, 35, 01006 (2018)

8. W. Korzeniowski, K. Skrzypkowski, K. Zagórski, Studia Geotechnica et Mechanica, 39, 1 (2017)

9. W. Pytel, Geomechanical problems of selecting rock bolt support for mining excavations (KGHM CUPRUM sp. z o. o. Research and Development Center, Wrocław, 2012)

10. J. Butra, Exploitation of copper ore deposit under the threat of rock bursts and roof falls (KGHM CUPRUM sp. z o. o. Research and Development Center, Wrocław, 2010)

11. www.arnall.com.pl, website of the company Minova Arnall Sp. z. o. o., access: 08.05.2018

12. K. Skrzypkowski, Ores and Non-ferrous Metals, 62, 5 (2017)

13. D. Kapuściński, G. Jankowski, K. Stoiński, III International Congress of Copper Ore Mining, Lubin (2015)

14. W. Korzeniowski, K. Skrzypkowski, Ł. Herezy, Archives of Mining Sciences, 60, 1 (2015)

15. W. Konopko, andA. Piernikarczyk, CUPRUM, 73, 4 (2014)

16. K. Skrzypkowski, Utility model no. PL 68412 Y1. Patent office, 5 (2016) 